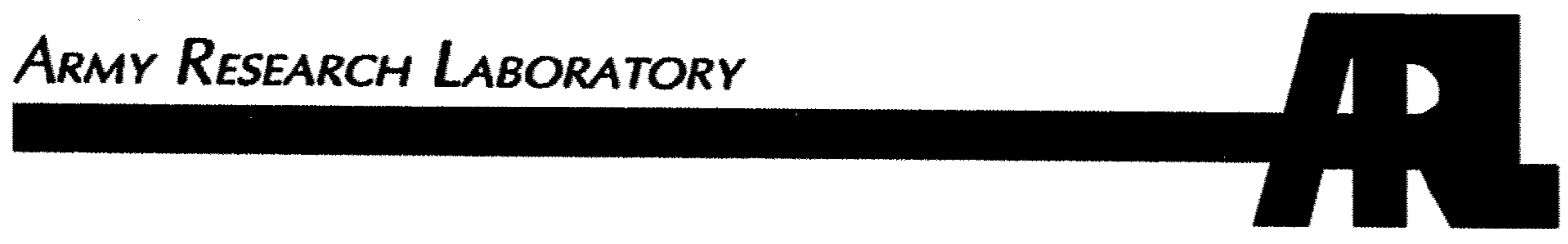

\title{
Cost Comparisons of Oven and Electron-Beam Processing Using Activity-Based Modeling
}

\author{
by Bernard F. Hart and James M. Sands
}

ARL-TR-2961

April 2003

Approved for public release; distribution is unlimited. 


\section{NOTICES}

\section{Disclaimers}

The findings in this report are not to be construed as an official Department of the Army position unless so designated by other authorized documents.

Citation of manufacturer's or trade names does not constitute an official endorsement or approval of the use thereof.

Destroy this report when it is no longer needed. Do not return it to the originator. 


\section{Army Research Laboratory}

Aberdeen Proving Ground, MD 21005-5069

\section{Cost Comparisons of Oven and Electron-Beam Processing Using Activity-Based Modeling}

Bernard F. Hart and James M. Sands

Weapons and Materials Research Directorate, ARL 
INTENTIONALLY LEFT BLANK. 


\section{Contents}

List of Figures $\quad$ iv

List of Tables $\quad$ iv

$\begin{array}{lr}\text { 1. Introduction } & 1\end{array}$

2. Cost Model Development 2

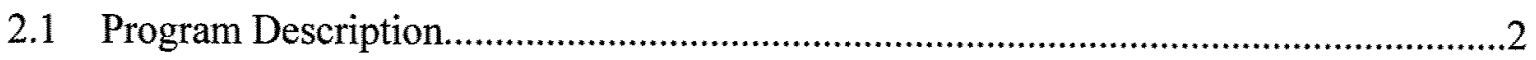

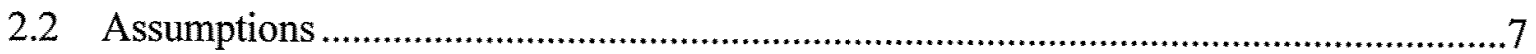

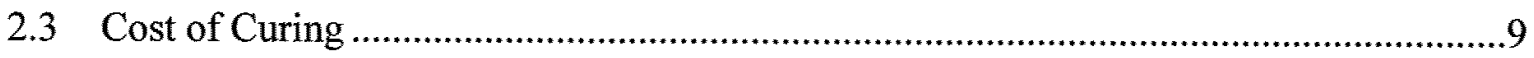

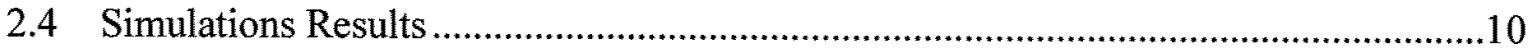

$\begin{array}{lr}\text { 3. Conclusions } & 13\end{array}$

4. References 16

$\begin{array}{lr}\text { Report Documentation Page } & 17\end{array}$ 


\section{List of Figures}

Figure 1. Cost model flow diagram for processing of VARTM composites using "oven" or "e-beam" to cure the composite structure................................................................................

Figure 2. A typical EB facility layout including accelerator, processing, and shipping areas. ......6

Figure 3. Typical arrangement for an (a) vertical processing scan horn and (b) processing

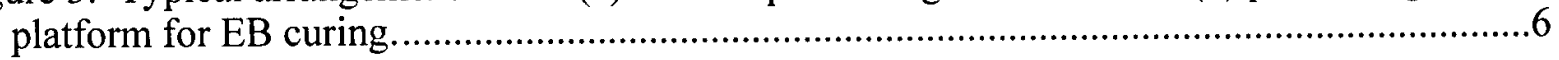

Figure 4. EB penetration depth (in water) for selected commercial beam energies.......................8

Figure 5. Production costs per square foot for EB ownership processing of flat panel composites (model 3).

Figure 6. EB processing of toll-based cure method for composite panels....................................12

Figure 7. Production costs per square foot of composite panels for thermally cured systems

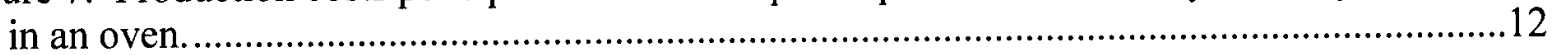

\section{List of Tables}

Table 1. Fixed cost data used to generate cost comparisons in EB vs. oven-cured VARTM composite panels. 10

Table 2. Model simulation systems and processing parameters. 10 


\section{Introduction}

In this report, a model compares the manufacturing costs associated with fabrication of a flatpanel glass composite plate using vacuum assisted resin transfer molding (VARTM) in combination with thermal oven curing or electron beam (EB) irradiation curing to process composite thermosets. By integrating process mapping, hierarchical event-driven simulation, and activity-based costing, the model determines the optimum conditions and the benefit or cost trade-offs associated with manufacturing performance composites using alternative curing technologies, such as EB curing. In the conclusion of the model evaluation, a determination is made that demonstrates the impact of resin cost on total manufacturing costs for the various components, and demonstrates how various scenarios from ownership to toll processing can be implemented by a manufacturer to keep total processing costs from EB curing relatively competitive with oven curing processes.

The basic model implemented for the following analysis is based on Scott Jones's co-injection resin transfer molding (CIRTM) model in SIMPROCESS ${ }^{*}$ (1). SIMPROCESS integrates process mapping, hierarchical event-driven simulation, and activity-based costing into a single tool and allows accurate computation of industrial costs to be determined under various imposed constraints and economic conditions. Activity-based costing embodies the concept that a business is a series of interrelated processes, and that these processes consist of activities that convert inputs to outputs. The cost modeling approach manifests this concept and builds on it by organizing and analyzing cost information on an activity basis. Although maintaining accurate accounting of every possible scenario of processing for the manufacturing demonstration is not feasible, the cost model implemented is relatively comprehensive. Local cost data were collected for labor, equipment, electric, fabric, resin, freight, toll charges, and the Maximum Achievable Control Technology (MACT) compliance cost (2).

Dynamic computer models were designed for VARTM composite processing of S-2 Glass ${ }^{\dagger}$ fabric using a vinyl ester and an EB resin with the option of oven or EB curing. Note that despite the understanding that autoclave processing is the worst-case pollution scenario, the model does not address this curing technology. The current emphasis on low-cost processing methods to develop thick-section composites compels a comparative study for traditional liquid molding rather than autoclave prepreg comparisons (3). The vacuum bagging employed by this process simulation was effective in minimizing hazardous air pollutant (HAP) levels to remain under the new MACT legislation of emitting no more than 10 tons/year of any single listed HAP at any single site, where a site is defined as a collection of related processing buildings (2). The National Emissions Standards for Hazardous Air Pollutants (NESHAP) legislation was

\footnotetext{
${ }^{*}$ CACI International, Ine., 1100 North Glebe Rd., Arlington, VA 22201.

${ }^{\dagger} \mathrm{S}-2$ Glass is a registered trademark of Owens-Corning Fiberglas Corp.
} 
implemented for U.S. industry in August 2001 and will begin to affect financial viability of commercial industries as early as 2005 .

In SIMPROCESS, a computer-generated manufacturing facility simulates the flow of raw materials and worker resources to create finished products using a three-shift working cycle that operates the plant $24 \mathrm{hr} /$ day for 1 calendar year. Among the key advantages to EB processing is the high cost of tooling associated with traditional thermal processing methods. Because the cost of tooling varies significantly with part size, part complexity, and dimensional complexity, the model does not attempt to add to this complexity. Therefore, costs are developed for fixed costs associated with thermal vs. EB processing for flat panel composites. Since net cost per part will be the most significant change associated with changing fiber types, the cost model is developed with only S-2 Glass fabric as the cost baseline. The finished parts from the model include various surface area panels ranging from 10 to $100 \mathrm{ft}^{2}\left(9290\right.$ to $\left.92903 \mathrm{~cm}^{2}\right)$, but keeping the thickness of all parts at a constant $0.75 \mathrm{in}(1.9 \mathrm{~cm})$. The impact of increasing surface area results in cost variations that are coupled with batch processing limitations for the thermal and EB cure techniques.

\section{Cost Model Development}

\subsection{Program Description}

SIMPROCESS employs processes, resources, and entities to construct a business model. A production plan was set up in the model to include laborers, equipment, and materials with a best practices approach to manufacturing that avoids overconstraining the resources or entities (e.g., having a resource either too busy or idle). People, materials, and equipment are examples of resources, while orders, fabric, completed parts, and work-in-process are examples of entities.

The basic flow diagram of the model is demonstrated in Figure 1. The model consists of three essential processing stages, which include preparation for manufacture and layup, curing, and finishing. Each of these segments contributes to the costs of manufacturing. However, due to the selected composite configuration, the greatest impact variables in the model include initial materials costs and equipment and curing costs. The steps occurring in each process phase of the model are described next.

The first step in the model involves setting up the production run. At the outset of production, a work order is generated, work scheduled, and materials procured to achieve optimum processing flow. A 24-hr, 7 day/week manufacturing schedule was utilized in the model, so all capital resources are used to the optimum limits. Next, the manufacturing work area was set up, including the cutting station and layup areas. Although this condition does not contribute to materials costs in the modeling, the activity (time) is a cost item for the laborers employed to perform the activity, adding to the total cost of manufacturing. 


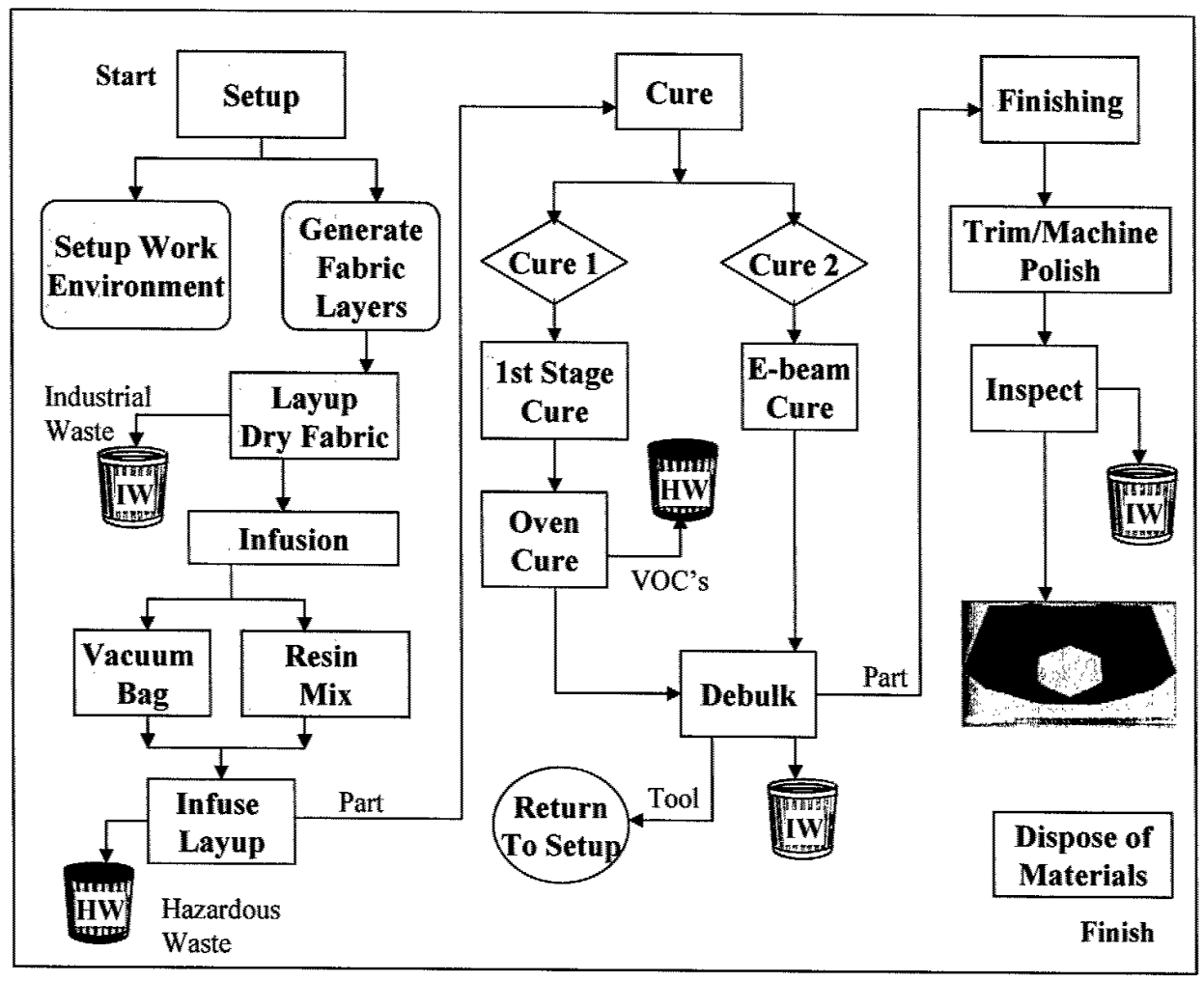

Figure 1. Cost model flow diagram for processing of VARTM composites using "oven" or "e-beam" to cure the composite structure.

Once the initial conditions for manufacturing are completed, the actual processing of materials components begins. Initially, the configurations of the manufactured part are determined, including number of layers of fabric required to make a part 0.75 in thick. With our selected part thickness, 29 layers of glass fabric were used. These parameters are passed along to the manufacturing cycle. The fabric layers required for assembling a part of a defined size are cut to size from the bolts and evaluated for quality assurance. The approved dry fabric pieces are stacked in the prescribed sequence, fiber aligned at the layup station, and placed into the part mold. Once the layer placement is inspected for quality, the dry fabric layup is completed. It should be noted that in addition to quality inspection, the model tracks scrap and poor quality materials that fail the inspection and is able to report waste materials amounts throughout the processing phase. As no resin materials are utilized to this point, waste fabric is considered an industrial waste, which is defined as nonhazardous materials waste from manufacturing production. Costs for disposal of the industrial wastes can therefore also be included in any detailed analyses.

Once a dry preform is established, the infusion process begins. The distribution medium and peel ply layers are cut and added to the mold configuration. As the process is modeling VARTM, the top layer of the mold is a vacuum layer, which for this study will be a disposable vacuum media. The vacuum bag was cut and installed around the part. The gates, vents, and infusion and vacuum 
lines were set up and installed. Once the configuration is completed, the dry preform is evacuated and the vacuum bag seal inspected for leakage.

After layup and mold preparations are complete, the resin mixture is prepared. Typical resin systems involve a two-component resin that is blended just prior to infusion. A limitation of the two-part resin is the limited processing window in which to infuse the part. The parameters associated with infusion time include the resin viscosity and the rate of change of viscosity, as well as any exothermic heat generated in the bulk resin. The model encompasses basic parameters for gelation time and initial resin viscosity to compute approximate infusion times for large parts. While the computation is not precise, a conservative estimate of total infusion time is achieved, which can be used to establish baseline production costs. During infusion, resin is supplied at atmospheric pressure. The pressure differential arising from the resin source at atmospheric pressure, along with the evacuated preform, stimulates resin impregnation of the fibrous preform. The infusion line was closed when the resin mixture started to gel. The parts were inspected after infusion. An additional feature of the production business model is included to track hazardous wastes and production wastes associated with the infusion process. As the raw materials in the resin are classified as hazardous materials, the wastes encountered with nonreacted resin are also considered hazardous wastes. Once the resin is cured into a solid waste, however, it is no longer considered hazardous material but is tracked as part of the industrial waste contribution to manufacturing. Such items as vacuum bags, distribution media, infusion lines, and incomplete parts are hazardous wastes. However, the manufacturing practice generally involves carrying infusion lines and infusion media into the curing phase with the composite part. As a result, the final status of most of these media is as industrial wastes.

It is worth noting that even during infusion, the EB and thermal systems behave somewhat differently, and therefore, each system is treated to a different curing schedule. The vinyl ester resin used in creating baseline data for the composite manufacturing is a two-part resin that has a limited out-time once mixed. By contrast, the EB resin selected for this study can be either a one-part resin with a low viscosity and no gelation without EB treatment, or a two-part resin that is handled similarly to vinyl esters with a limited processing time, but which fully gels at room temperature. In the case of the EB resins, the assumption is employed that the resin does gel before EB is applied, and therefore, the assembled part and all infusion and layup components need not be shipped to the EB facility for toll-based curing, nor transported to the EB curing stage for ownership-based curing. In all cases, the EB layups are not heated, and therefore, no oven is used for EB manufacturing. In recent experimental developments, however, it has been demonstrated that oven postcuring of EB cured resins produces improved materials performance in the final composites, without sacrificing dimensional tolerance advantages associated with EB curing $(4,5)$.

After infusion, thermal cured assemblies were cured for $2 \mathrm{hr}$ at $140^{\circ} \mathrm{F}$ (First Stage Cure). The purpose of this curing stage is to stage the resin into a lightly linked gel state. The lower processing temperature prevents rapid acceleration of the thermal curing, which can result in 
exothermic conditions and run away reactions that cause explosive or combustive conditions. Once the materials are staged through vitrification, the energy associated with crosslink formation in the resins is released at a much slower rate, allowing for higher postcure temperatures. A similar limit exists for EB cured resins; however, in the case of EB cure, changing the applied dose-rate controls the exothermic heating. Dose rates from 0.5 to $10 \mathrm{Mrad} /$ pass are common processing ranges for composites, with thicker parts requiring lower dose/pass equivalents. Also, for two-part EB resins, the room temperature staged resin is sufficient to prevent substantial exothermic conditions from developing, allowing higher dose/pass for initial treatments. The EB cure cycle assumes a total applied dose of $20 \mathrm{Mrad}$, a number demonstrated to fully convert accessible functional groups in all the resins developed for EB processing. As a cost factor, the total number of passes required to reach an applied dose of $20 \mathrm{Mrad}$ increases the processing time for EB curing, and contributes to higher costs and greater user burden on the EB resource. The minimum number of passes is used in the model, so a best-costs scenario is created for EB.

The infusion media and infusion lines were discarded after this first cure operation for the vinyl ester parts, while these materials were maintained throughout the processing phase for EB components. The thermally staged vinyl ester composites were separated from the mold after vitrification as vacuum pressure could be released without spring-back or deformations occurring to the structures. The mold was subsequently prepared and returned to the beginning of the manufacturing cycle. The EB system was fully cured under EB prior to returning the molds for reuse. It is relevant to note in this analysis, that because VARTM molding is used, no effort was undertaken to reduce mold costs for EB processing, despite the understanding that high-cost molding is among the cost savings for EB vs. conventional resin transfer molding. The VARTM aspect eliminates this advantage between the two test conditions selected. The next step in the thermal cure is a postcure of the vitrified parts. Parts were held for $3 \mathrm{hr}$ at $250^{\circ} \mathrm{F}$ in the oven.

Another aspect of the processing that impacts the costs of manufacturing dramatically is the effect of batching in the curing phase. For the oven-cured vinyl esters, the batch size was dependent on both the oven size and the part size. The number of parts that were committed to the oven is based on the available volume and the oven-to-part dimension analysis. For the EB cure, the batch size was dependent on the vault configurations, the cart size, and the part size. Recognize also that volatile organic compounds (VOCs) may be emitted during oven curing due to the open cure environment and the commercial formulations of the vinyl ester resins. The EB-cured part, however, does not have VOCs as the resins are designed with $100 \%$ nonvolatile elements, providing for improved environmental control. The cycle time for the EB curing depends on the applied dose, the part size, and the size of the track for the EB vault (e.g., number of carts in the processing train). A typical EB processing warehouse is shown in Figure 2, where the EB source is shielded to prevent radiation exposure to the users. The processing zone is reached through a conveyor system that translates the parts into a vault for curing. A vertically mounted $\mathrm{EB}$ horn inside a vault area is shown in Figure 3. The conveyor is also shown with a sample panel mounted in the beam path. The conveyor system can be either a pass through or directional type, as shown. 


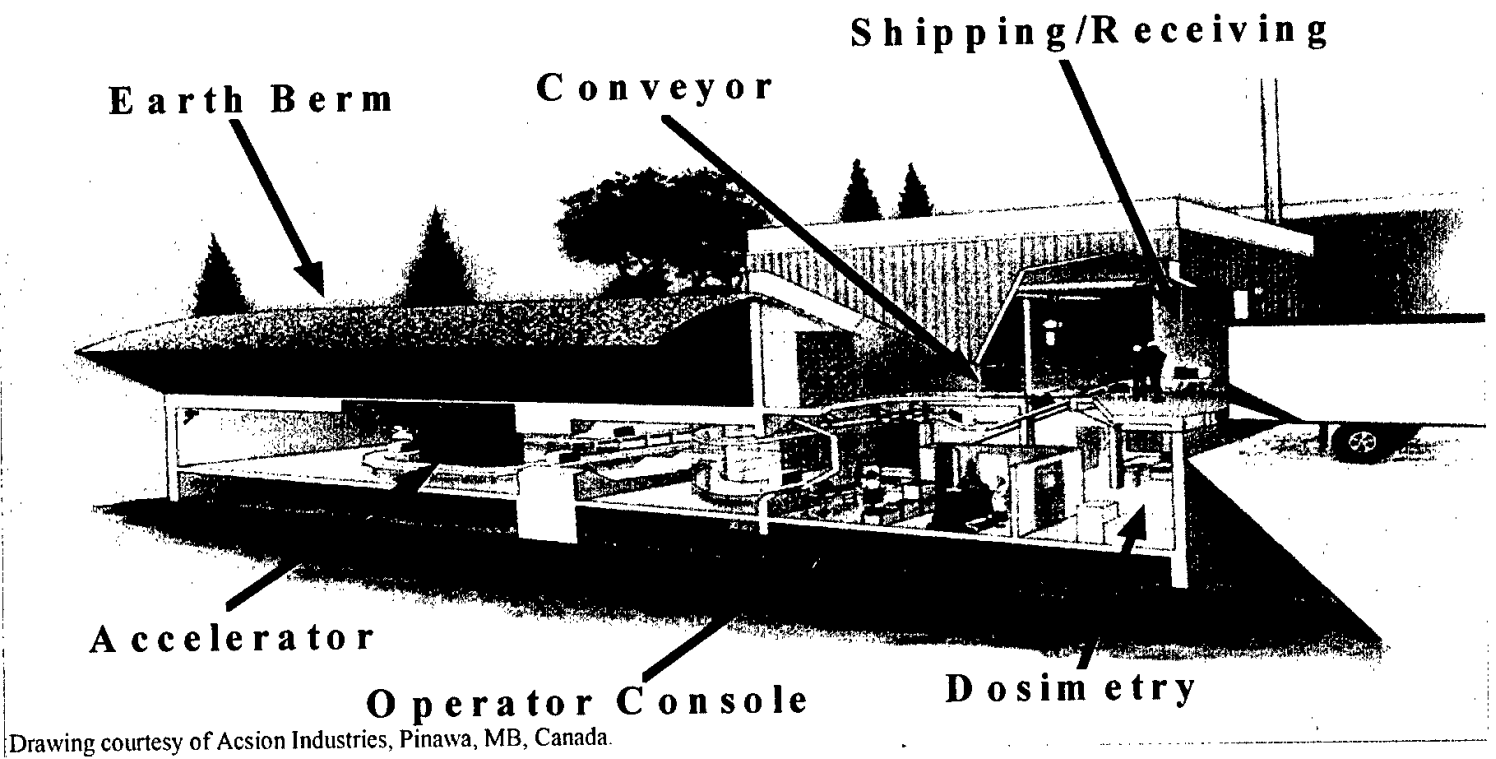

Figure 2. A typical EB facility layout including accelerator, processing, and shipping areas.

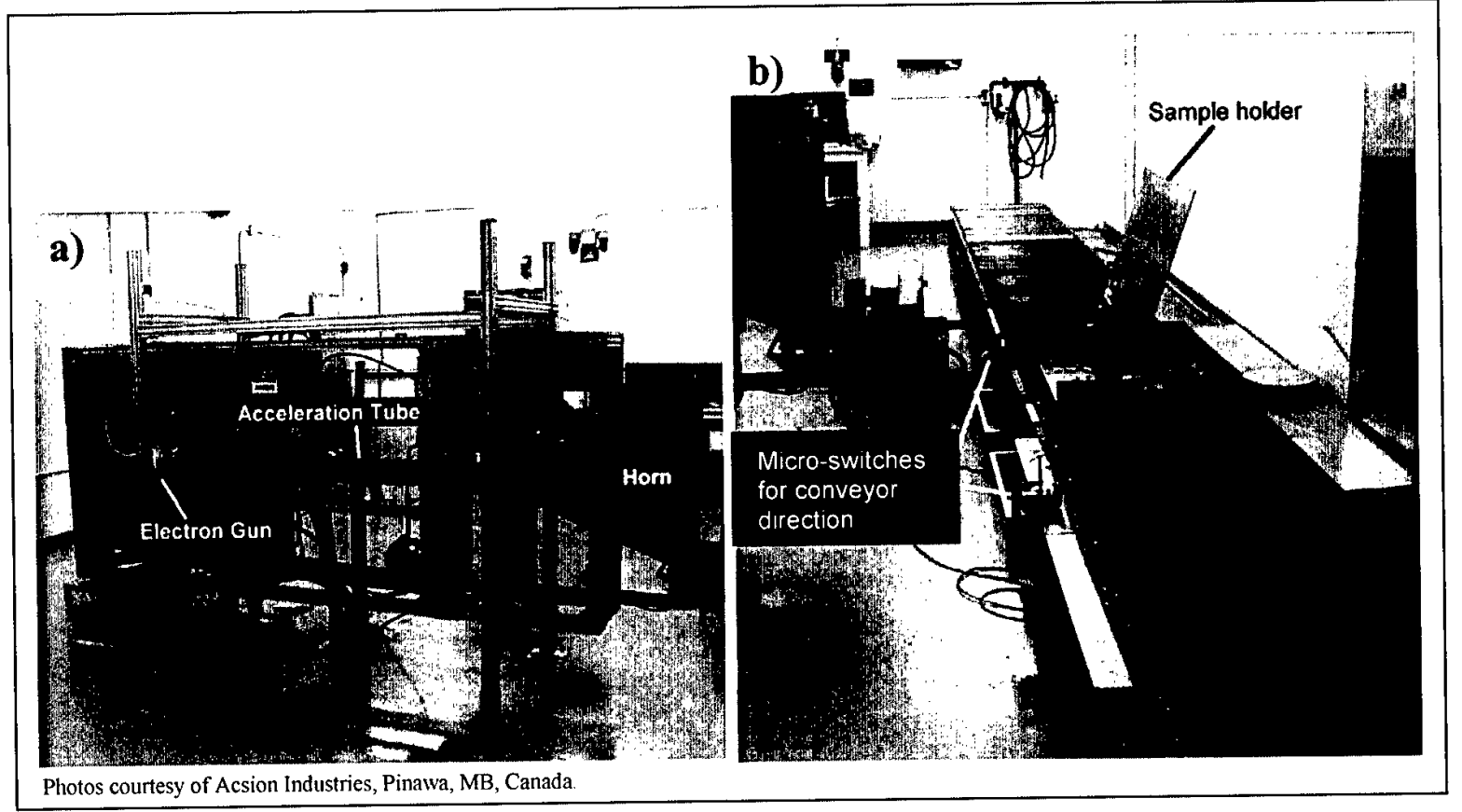

Figure 3. Typical arrangement for an (a) vertical processing scan horn and (b) processing platform for EB curing.

The advantages of vertically mounted processing are increased processing size capability and potential for rotational design implementations for curing of asymmetric structures. The advantages of a directional conveyor include the ability to shuttle a part quickly across the beam multiple times to apply doses rapidly in incremental amounts. The model for EB curing assumes a pass-through processing conveyor, where the component receives a given dose for each pass around the conveyor track (nonshuttling). This method means that a single part will require 
nearly identical processing times to multiple parts, where a train of components can be sent continuously through the beam. Therefore, in the models, costs for processing using EB are approximately constant up to the number of cars that reside in the processing conveyor.

Once the EB and oven materials are cured, the composites are debulked from the curing tools and sent to a finishing stage. During finishing, excess material resulting from the vacuum infusion method is trimmed away from around the perimeter of the part. This trim is considered an industrial waste for both techniques as the resin is fully cured. The trimmed part is inspected, repaired (if necessary), and submitted to further cost-equivalent processing stages. For example, for a composite panel that will be joined with other manufactured specimens, holes are machined through the part at the finishing stage. The machined part is inspected and repaired as needed. Once inspected and approved, the part is considered a finished component and goes into the manufactured count. The time to perform trimming and machining was not a consideration for the model comparison as both materials were treated similarly, therefore not impacting cost variation to the processing.

\subsection{Assumptions}

The basic calculation for manufacturing cost involves a summation of all capital costs. The capital costs include labor, equipment, and materials costs. Once a net cost is established for a given manufacturing cycle (number or parts), the cost per unit is calculated to normalize all processing costs. A comparative plot of cost per unit as a function of manufactured units is a part of the cost analysis.

A number of computational assumptions were required for each of the processing methods selected. Since the initial cost conditions will be carried into final product cost through a depreciation and maintenance contribution, the initial costs datum play a significant role in the cost per unit. For this study, an oven of reasonable size to cure the largest manufactured part is selected and cost averaged for the model. Blue M Company ${ }^{*}$ provided the oven costs $(6)$. The oven specifications include a $60-\mathrm{kW}$ oven with a chamber dimension of $12 \times 12 \times 6 \mathrm{ft}$ with 10 removable shelves. The addition of removable shelves allowed for increased batch sizes for smaller parts. It is demonstrated that batching of components can substantially lower net costs of manufacturing for oven-processed components. The effect of processing delays on performance of the composites is not considered a factor in the modeling developments. Oven batch sizes of $1\left(60\right.$ and $\left.100 \mathrm{ft}^{2}\right), 20\left(24 \mathrm{ft}^{2}\right)$, and $80\left(10 \mathrm{ft}^{2}\right)$ parts were used in the models.

The EB processing is significantly more complex than the oven method. A consequence of the complexity of EB processing is worker safety, which requires substantial shielding of the processing zones in order to protect from stray radiation. Therefore, the work environment used to calculate costs includes both a processing unit and the required shielding. Additionally, a transport mechanism is required to move the fabricated parts through the EB process chamber.

\footnotetext{
*Blue M Company, 2121 Reach Rd., Williamsport, PA 17701.
} 
Each of these features contributes significantly to the final installed cost of an EB facility. Two cost functions are included for this analysis. One approach assumes an initial capital outlay to purchase an EB processing unit for the manufacturing facility. This approach gives direct manufacturing cost comparison to the oven processing approach described. A second approach is based on the recognition that resource time for an EB unit in this facility is severely underutilized. Consequently, a calculation is made assuming that existing EB facilities are used to cure the composite structures. This second case then incorporates expected additional costs associated with transport of the resin impregnated and cured composites to and from the manufacturing floor from the $\mathrm{EB}$ contract facility. Costs for transport are acquired from $\mathrm{CF}$ Motor Freight $^{*}(7)$.

The purchased EB gun and electronics is a $150-\mathrm{kW} \times 10-\mathrm{MeV}$ unit. The high-energy electrons allow a uniform dose to be applied from one side of the 0.75 -in-thick composites as shown in Figure 4. The penetration is dependent upon structural density. The case for $1 \mathrm{~g} / \mathrm{cm}^{3}$ is shown in the figure. The cost of such a high energy unit is not substantially greater than for a $5-\mathrm{MeV}$ system, as the total costs of acquisition include shielding and vault design, which are $50 \%$ of the total purchase cost. The vault is typically constructed either using an earthen berm, or more commonly, lead impregnated concrete walls. The particular configuration must be capable of housing a composite structure of $100 \mathrm{ft}^{2}$ on a continuous cycle. The costs of construction for an EB facility were provided from average facility costs calculated by $\operatorname{IBA}^{\dagger}(8)$.

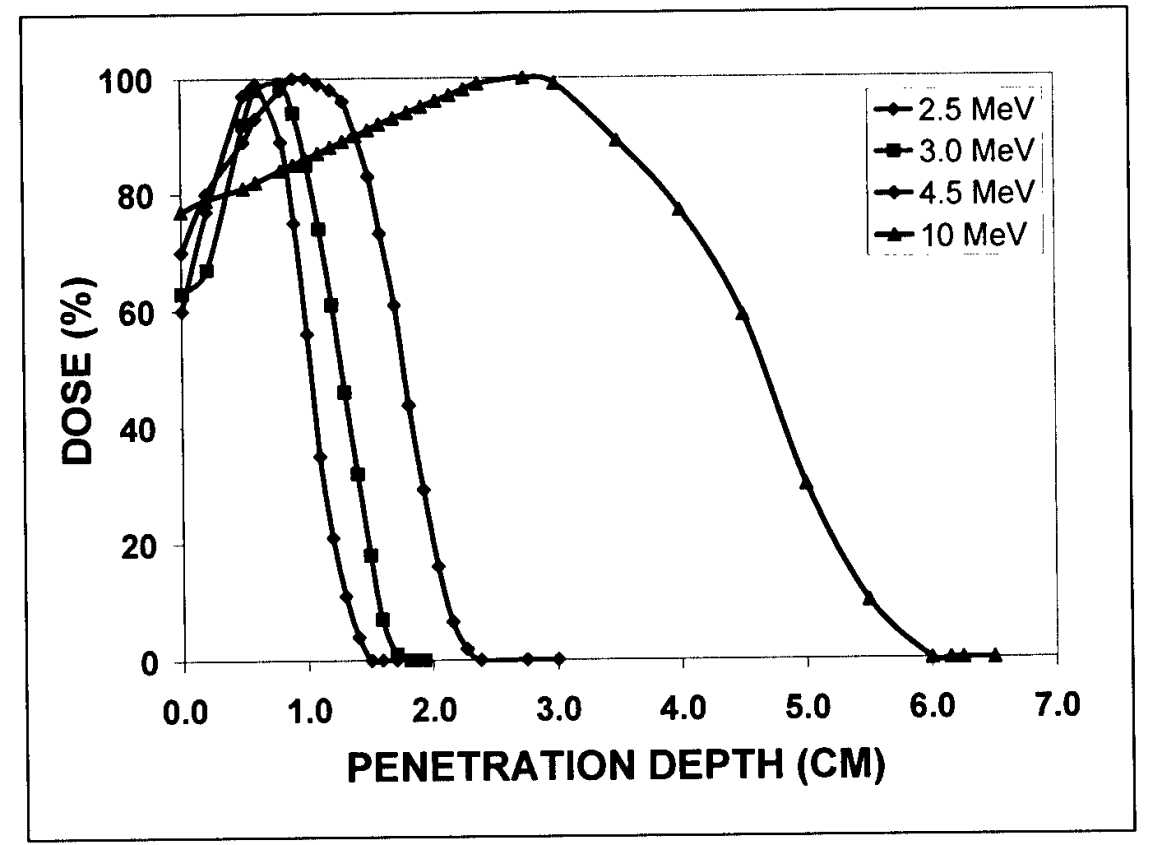

Figure 4. EB penetration depth (in water) for selected commercial beam energies.

\footnotetext{
* CF Motor Freight, 3663 Benson Ave., Baltimore, MD 21227.

${ }^{\dagger}$ IBA, 303 Horn Dr., Swedesboro, NJ 08085.
} 
In order to keep costs comparative, a similar EB configuration was used to generate toll-based costs for EB processing. A $150-\mathrm{kW}$ and $10-\mathrm{MeV}$ EB was assumed and the costs of transport were included assuming a contract with the toll facility of E-Beam Services, Inc. ${ }^{*}$ The vault developed for the EB Services, Inc. facility is the largest available in the industry in the USA. The facility permits a $10-\times 10-\mathrm{ft}$ part continuous entrance and exit with good production efficiency. The transport carts are $52 \times 100$ in, which provides $\sim 60 \%-70 \%$ utilization of the beam spread depending on part size. EB parts were also batched in the processing model to obtain maximum efficiency when the beam is on. Batch sizes of $40\left(10 \mathrm{ft}^{2}\right), 20\left(24 \mathrm{ft}^{2}\right)$, and 10 $\left(60\right.$ and $\left.100 \mathrm{ft}^{2}\right)$ were used.

\subsection{Cost of Curing}

With the selected equipment, the total costs for ownership-based operation of the equipment are figured based on two calculations. The first calculation is the real-time use fact, which is based on the average electric consumption for the operations. To establish baseline costs for electric use, a cost figure of $\$ 0.064 / \mathrm{kWh}$ was assumed, based on electric costs from the University of Delaware. ${ }^{\dagger}$ This number is approximately equivalent to the national average for electric costs per kilowatt-hour. A computation of costs of operation per cure cycle could then be determined from the power rating of the equipment and the time required to achieve full cure. The second calculation used in the model is a depreciation and maintenance factor. These numbers are acquired from the commercial entities supplying the equipments and include average useful life of the equipment and annual maintenance issues associated with the equipment.

For toll-based processing using EB, the facilities owners assume costs for electricity and maintenance. Therefore, a toll-based charge is assumed based on time required for curing of the composite parts. However, with toll-based processing, the additional costs of transportation are added to the formula. Freight charges are calculated based on class of material being shipped, weight of products shipped, and locations of the shipping and receiving facilities. A significant cost break is achieved with loads exceeding $100,000 \mathrm{lb}$. The charges used in the model are for shipping from the U.S. Army Research Laboratory at Aberdeen Proving Ground, MD to the EB Services, Inc. facilities in Cranbury, NJ. A toll charge to apply a 20 -Mrad dose requires $\sim 50 \mathrm{~min}$ to achieve at a nominal rate of $\$ 750$ for 10 - and $24-\mathrm{ft}^{2}$ parts. The time to cure increases with part size and complexity, as the beam spread is adjusted to meet the width requirements. Widening the beam has an effect of decreasing dose rate, causing longer cure cycles. Therefore, for each beam parameter change, EB Services, Inc. provided approximate cure times and costs. Processing costs were $\$ 825$ (61 min) for $60 \mathrm{ft}^{2}$ and $\$ 1650(122 \mathrm{~min})$ for $100 \mathrm{ft}^{2}$. It should be mentioned that the ability to cure $100-\mathrm{ft}^{2}$ parts is limited for a single horn configuration. Therefore, in the model, we assume the ability to cure onehalf of the part and rotate the position under the scan horn and cure the additional half of the part. The need for the additional passes greatly increases the time required to cure the large parts.

\footnotetext{
*E-Beam Services, Inc., 118 Melrich Rd., Cranbury, NJ 08512.

University of Delaware, Newark, DE 19716.
} 
The final calculation included in the model is relevant only to the thermal cured system. Due to the nature of VARTM resins in general, a compliance cost was assumed to address emissions costs from liquid molding in the composite panels. Should a vinyl ester-type resin be selected for the thermal processing, emissions of styrene will potentially add to the total costs of production. Therefore, a compliance cost is calculated based on output volume and using the MACT 2004 tax base of $\$ 0.24 / \mathrm{lb}$ of composites ( 9 ). The results show that this effect would be minimal for processing under VARTM conditions.

Table 1 summarizes the fixed cost figures used in the models to generate comparative data between EB-ownership, EB-toll, and oven processing of flat plate composites of various sizes.

Table 1. Fixed cost data used to generate cost comparisons in EB vs. oven-cured VARTM composite panels.

\begin{tabular}{|c|c|c|c|}
\hline Costs/Charges & EB Toll & EB Ownership & Oven Ownership \\
\hline Electric & None & $\$ 0.064 / \mathrm{kWhr}$ & $\$ 0.064 / \mathrm{kWhr}$ \\
\hline Resin & $\$ 10 / \mathrm{lb}$ & $\$ 10 / \mathrm{lb}$ & $\begin{array}{c}\$ 1.60 / \mathrm{lb} \text { bulk } \\
\$ 3.10 / \mathrm{lb} \text { catalyst } \\
\$ 3.71 / \mathrm{lb} \text { accelerator } \\
\$ 3.95 / \mathrm{lb} \text { inhibitor }\end{array}$ \\
\hline Fabric & $\$ 6.30 / \mathrm{lb}$ & $\$ 6.30 / \mathrm{lb}$ & $\$ 6.30 / \mathrm{lb}$ \\
\hline Labor-skilled & $\$ 70 / \mathrm{hr}$ & $\$ 70 / \mathrm{hr}$ & $\$ 70 / \mathrm{hr}$ \\
\hline Labor - unskilled & $\$ 60 / \mathrm{hr}$ & $\$ 60 / \mathrm{hr}$ & $\$ 60 / \mathrm{hr}$ \\
\hline Labor - supervisor & $\$ 70 / \mathrm{hr}$ & $\$ 70 / \mathrm{hr}$ & $\$ 70 / \mathrm{hr}$ \\
\hline MACT & None & None & $\$ 0.24 /$ lb composite \\
\hline Depreciation/maintenance & None & 10 years at $\$ 300 \mathrm{~K} /$ year & 10 years at $\$ 5700 /$ year \\
\hline Purchasing & None & $\$ 3 \mathrm{M}$ & $\$ 57 \mathrm{~K}$ \\
\hline Toll & $\sim \$ 800 / \mathrm{hr}$ & None & None \\
\hline $\begin{array}{c}\text { Process shipping } \\
<100 \mathrm{k} \mathrm{lb} \\
>100 \mathrm{k} \mathrm{lb}\end{array}$ & $\begin{array}{l}\$ 0.16-2.08 / \mathrm{lb} \\
\$ 0.14-0.16 / \mathrm{lb}\end{array}$ & None & None \\
\hline
\end{tabular}

\subsection{Simulations Results}

The variations of model systems that were investigated are described in Table 2. The basic context of the models was discussed previously. The results of various parameter variations from the proposed experiments will be discussed here. The model studies will be referred to frequently by either the process method or by the model number identification shown in the table as part of the discussion.

Table 2. Model simulation systems and processing parameters.

\begin{tabular}{|c|l|l|}
\hline Model No. & \multicolumn{1}{|c|}{ Resin System } & \multicolumn{1}{c|}{ Curing Method } \\
\hline 1 & Vinyl ester or epoxy & $\begin{array}{l}\text { Oven-cured, 2-hour staging at } 140^{\circ} \mathrm{F} \text { followed by 3-hr } \\
\text { cure at 250 }{ }^{\circ} \mathrm{F} \text {. }\end{array}$ \\
\hline 2 & $\begin{array}{l}\text { Cationic cured epoxy } \\
\text { or methacrylate }\end{array}$ & $\begin{array}{l}\text { EB cured, toll-based processing adding 20 Mrad over } \\
\text { entire surface area. Includes shipping costs. }\end{array}$ \\
\hline 3 & $\begin{array}{l}\text { Cationic cured epoxy } \\
\text { or methacrylate }\end{array}$ & $\begin{array}{l}\text { EB cured, ownership-based processing adding 20 Mrad } \\
\text { over entire surface area. }\end{array}$ \\
\hline
\end{tabular}


Figure 5 shows the processing costs per square foot of 0.75 -in composites manufactured for EB processing for ownership of the EB facility as a function of total production volume. A few key items are easily discerned. First, initial costs in manufacturing the first part are higher per unit for the first 10 parts. However, after 10 parts are processed, production costs level off to a constant per unit cost. Second, the cost per square foot is lower for larger composite panels, but average costs level off toward larger parts $\left(>60 \mathrm{ft}^{2}\right)$. The leveling point is related to the balance between batch size and resource availability for processing of parts of this size. Lastly, the time variation between the cost of the first unit produced and the second unit produced is smaller for increased part dimensions.

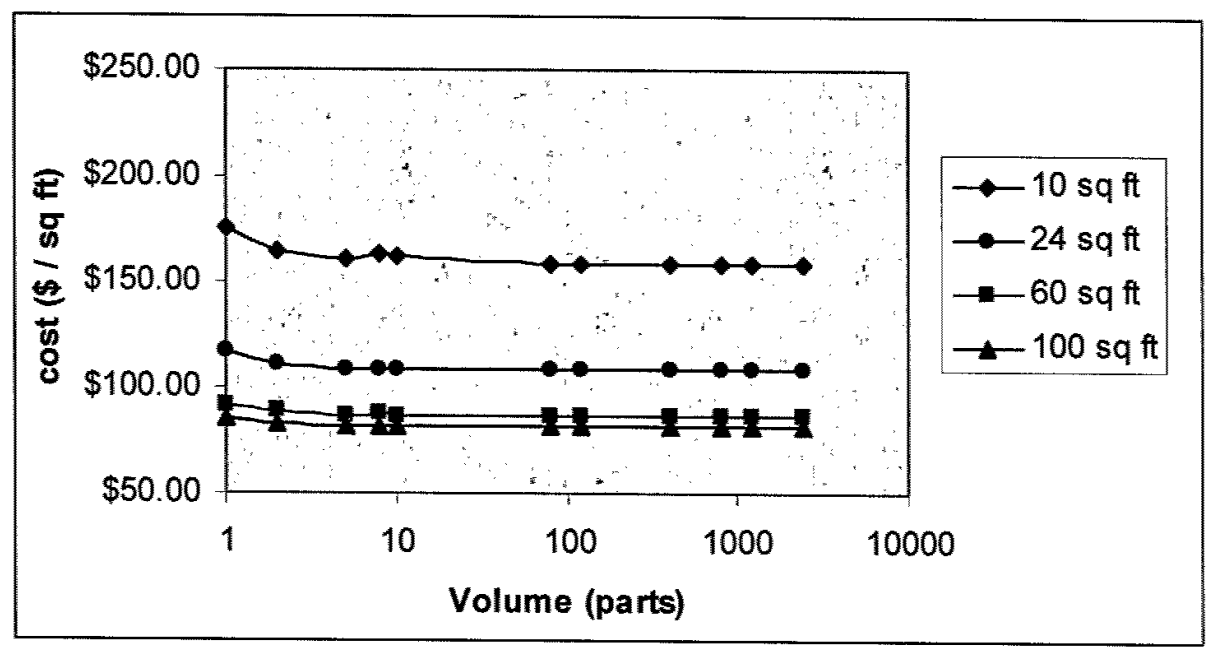

Figure 5. Production costs per square foot for EB ownership processing of flat panel composites (model 3).

Toll-based EB processing has long been believed to be an excellent entry level processing approach for composite structures. In order to validate the processing value of EB toll vs. ownership, the net cost of producing the same composite parts is determined for a non-ownership case. Figure 6 shows the cost per square foot for the same composite structures processed using a facility toll EB source. One clear trend is the high cost of processing for just a single unit. Although performing one- and two-part layups is not a manufacturing cycle, these costs accurately reflect the cost of performing repair of a composite panel as well. Consequently, the evidence for using toll-based processing for repair is also demonstrated in the present model. Again, costs level out for larger production runs. For this special case, however, the costs level out at higher production numbers for the smaller parts, reflecting the advantage of fee-based processing. Since the cost per hour is constant, cycling multiple parts under the EB scan-horn to apply doses continuously across many parts reduces the net cost per part until the beam usage is maximized. 


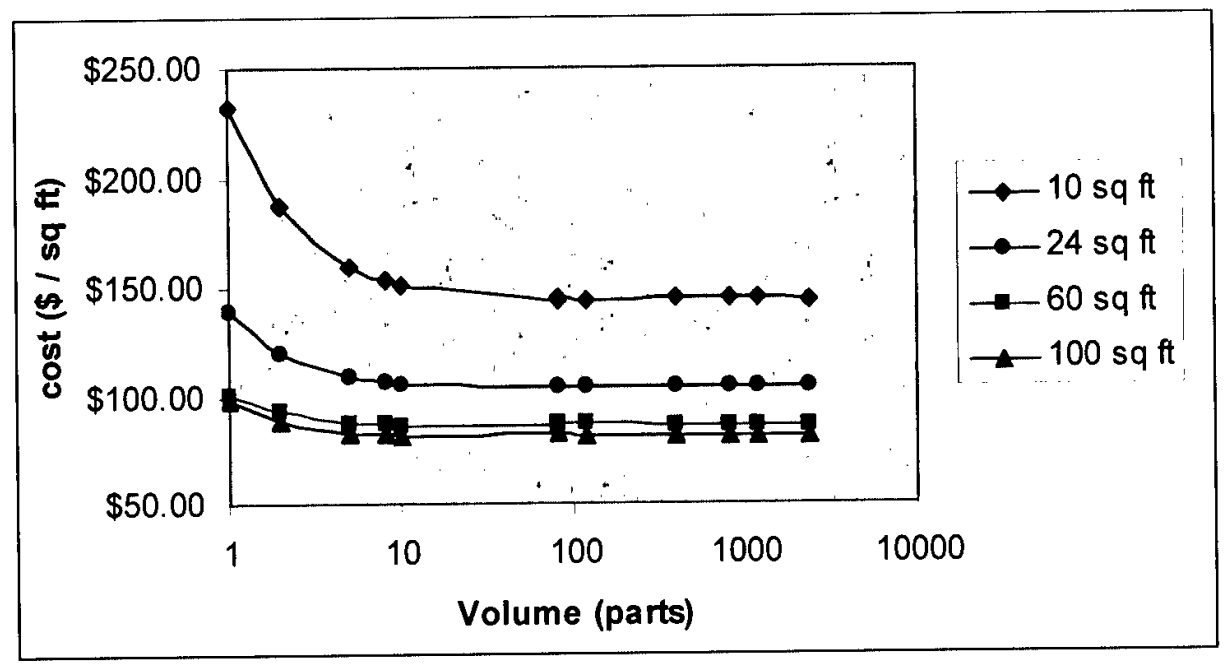

Figure 6. EB processing of toll-based cure method for composite panels.

The final comparative case is for oven-based processing. Due to the low-cost nature of the oven, only an ownership case is considered. The processing cost per square foot using an oven for the same panels is demonstrated in Figure 7. Immediately evident is the lower cost associated with low-volume production. Additionally, the advantages of batch curing are evident for process runs including more than 10 production units. A key technical barrier that is not captured by this study, however, is the effect of generating parts larger than the oven capacity. Unlike EB, which can be varied to achieve cure in large structures, the oven dimensions are fixed. Once the scale of parts exceeds the oven dimension, additional capital costs will be required. Consequently, the decreasing cost per square foot with size has reached a minimum in the case of $100-\mathrm{ft}^{2}$ parts for our selected oven. To prepare a $1000-\mathrm{ft}^{2}$ part, the model will require adjustments and additional capital depreciation and maintenance costs that will increase the average costs substantially. Again, however, it is apparent that increasing the volume beyond 1000 parts will not decrease costs per unit significantly unless additional resources are added.

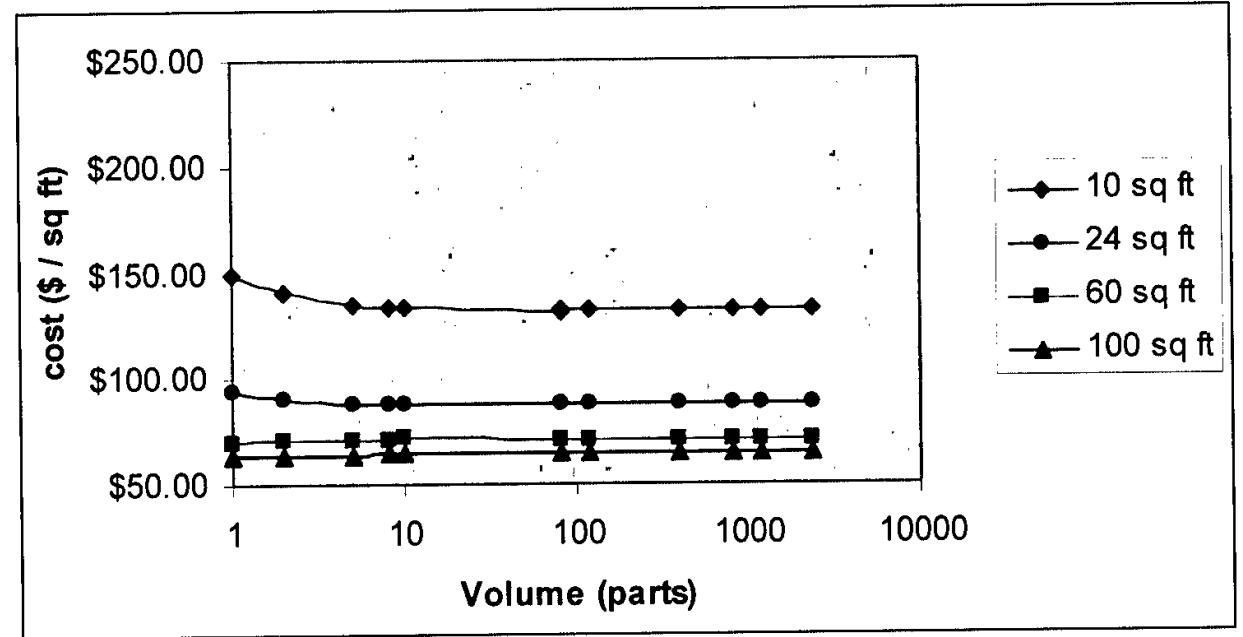

Figure 7. Production costs per square foot of composite panels for thermally cured systems in an oven. 
The current cost model does not consider costs of tooling variations between EB cured and thermal cured composite structures. Due to tolerance issues in the manufacturing process, tooling costs can reach millions of dollars per unit for thermal cured composites as metallic tools are often created with defined coefficients of thermal expansion (CTE) that closely mimic composite cure shrinkages. The advantage of these high-cost tools is in generating extremely tight tolerances in the fabrication of composite structures. However, for VARTM processing, this level of tooling cost is eliminated, as the VARTM processing is inherently less precise. The cost of autoclave curing could also be investigated, but without introducing additional tooling costs, or impacts of size limitations on the autoclave purchasing costs, the results would show a similar trend.

\section{Conclusions}

Some key conclusions that result from this modeling evaluation are the impact of capital costs on net processing costs and the minimal impact that compliance charges would have on final product cost, given the current regulations and tax rates. The impact of MACT on the small manufacturer is likely to be more substantial than on military providers, due in part to volume differences. However, as the military adds additional low-cost composite materials to the fielded platform portfolio, additional production suppliers will be essential to meet the increased demand (volume), and commodity composite fabricators will be strongly impacted in supplying military equipment. Additionally, the Army currently is developing a composite replacement parts program entitled "Composite Body Parts," where sheet metal components with high corrosion replacement rates will be re-engineered using low-cost composite alternatives. Currently the program is in developmental funding. The components developed in the program will provide extensive insertion of composite media to the Army legacy infrastructure.

Although, EB processing has the potential to produce a higher number of total parts, the lack of high-volume applications for large composite products in the military will cause the need for instantaneous throughput to be a minimal cost benefit for the producer. The EB processing unit is utilized at only about $5 \%$ of capacity in the model demonstrated, while other composite fabrication items are used to their full potential. Therefore, the processing bottleneck occurs in layup rather than cure process resources. Coupled with the shorter curing times and decreased energy consumption, the impact of a high-volume EB processing unit is a greater turn-over rate, and faster time to market for a given structure. However, the cost benefit of rapid production rates is not realized in full due to limited production volumes outlined in the process model. Additionally, the stability of EB resins and long shelf life provide a substantial reduction potential for hazardous wastes. The oven-processed resin is extremely time-sensitive once the raw materials are blended, causing a high potential for excess wastes in the infusion process. The value of stability to achieving optimum fill volumes and highly reproducible components is 
also not captured in the process models as described. Consequently, the worst-case scenario for EB processing has been explored, and under a worst-case comparison, EB processing will be significantly more costly due to high initial capital and high resin costs, compared to current thermal processing methods. Environmental controls and regulations alone are not significant enough to convince commercial industry to recapitalize equipment and change processes for current process methods.

Again, a key advantage to new EB processing technology is a reduction in compliance restraints on a commercial enterprise. The EB resins are among the few viable resin formulations that effectively meet highly restrictive California emissions requirements (10). There are no VOCs emitted due to the $100 \%$ solids content of resins used for EB cure applications. The environmental value of non-emitting resin systems will continue to be a value added benefit for future composite developers, even though current technical performance metrics do not warrant changing current processing methods. Commercial industry should keep pursuing new cure technologies for composite applications in new product venues, in order to maximize environmental responsibility and provide optimum value for the composites customer.

Two bases effectively drive the higher costs of $\mathrm{EB}$ processing: resin cost and equipment cost. In the case of ownership for EB vs. oven, the EB equipment costs 50 times more than a typical oven. However, the oven resource is utilized at $\sim 60 \%$ of availability, while the EB unit operates at only $5 \%$ of capacity. Although the usage rates vary significantly, the model did not account for the increased service life of the EB unit. Effectively, the processing costs for EB could be reduced by a factor of 12 for a direct comparison with oven. However, the authors believed that extending EB service life into 100 years was unrealistic and would not effectively capture cost trends. Therefore, the highest reasonable capital cost depreciation and maintenance was applied, which elevated the EB processing costs. Second, the resins available for EB are not in high demand. The lack of commercial competition for manufacturing of EB resins additionally caused resin costs to be high. Without the implementation of commercial enterprise to drive costs down, EB resins are assumed to remain at a premium price rate for some duration. A reasonable assessment of the resin costs should allow for reducing costs with increasing volumes of commercial product produced. This aspect of the market effect on material costs could also not be reliably implemented in the model system. A key finding from the model, however, demonstrated that even using a relatively high-cost thermal system, the average resin cost per square foot is four times as high for EB systems, due to the volume discounts available on thermal resins. Upon analysis of a 1-year processing cycle for EB or oven ownership, the total costs for materials are $72 \%$ of net operating cost for EB vs. only $61 \%$ for the thermal cured case. This difference is difficult to overcome when total compliance costs account for only $\sim 1.25 \%-1.5 \%$ of final part costs. The initial resin costs cannot be recovered without the incorporation of tooling based costs in the models. Unfortunately, EB and oven comparisons for VARTM processing will inevitably demonstrate lower production costs for the oven-processed case as a result. 
In summary, the model analysis shows clearly that under current developmental status of EB for composite applications, the effective cost of production for composite structures will be somewhat higher using EB.

EB processing is still a very cost effective processing technology for certain niche market applications. For instance, composite designs where net shape parts are essential would benefit greatly from the advanced resin designs afforded through EB processing. Additionally, composite structures composed of dissimilar materials or asymmetric interfaces could be created and cured using EB, producing novel structures that are not achievable using thermal methods. The aforementioned analysis also demonstrates a cost comparison with the lowest cost basis of processing currently available, i.e., low-cost resins with low-cost VARTM infusion. To apply EB technology to more advanced processing techniques such as prepreg or RTM layup methods would further improve the cost factors in favor of EB methods. However, for the current analysis, thermal processing methods still appear to be a preferred method of achieving low-cost processing of thick-section composite structures through VARTM of flat panel materials. Additional developments in the niche market environment for EB processing are currently underway, where an emphasis on environmental stability and low-shrinkage with lowtemperature processing can be essential to achieving complex geometries with exceptional tolerances. The future of EB is indeed bright, despite cost challenges uncovered under this model evaluation. 


\section{References}

1. Hosur, M. V.; Vaidya, U. K.; Jeelani, S.; Jones, S.; Eduljee, R.; Gillespie, J., Jr. Activity Based Cost Modeling of Liquid Molding Processing Techniques for Thick Section Composites. In Proceedings of American Society for Composites 14th Technical Conference, Dayton, OH, Sept 27-29, 1999; pp 968-977.

2. Guidance on Clean Air Act Title III Regulations: National Emission Standards for Hazardous Air Pollutants for Source Categories. Code of Federal Regulations, Part 63.463, Title 40, 2001.

3. Wilenski, M. Non-Autoclave Materials for Large Composite Structures; Progress Report to Air Force for Contract No. F33615-99-C-5019; Nov 16, 2000.

4. Carstensen, T.; Rogg, C.; Wilenski, M.; Aiken, R. Electron Beam Curing of Secondary Structural Aircraft Components. Presented at the SAMPE 2002 Symposium and Exhibition, Long Beach, CA, May 12-15, 2002; Closed Paper.

5. Wilenski, M.; Baker, C. Process Development of E-Beam Curing for Large Structures. Presented at the SAMPE 2002 Symposium and Exhibition, Long Beach, CA, May $12-15,2002$.

6. Savage, K. Blue M Company, Williamsport, PA. Private communication with Bernard Hart, April 2002.

7. Sales Associate. CF Motor Freight, Baltimore, MD. Private communication with Bernard Hart, May 2002.

8. Cheng, S.; Kerluke, D. IBA, Swedesboro, NJ. Private communication with James Sands at SAMPE 2002 Symposium and Exhibition, Long Beach, CA, May 14, 2002.

9. Schweitzer, J. The Cost of Control. Composites Fabrication, June 2001, pp 10-43.

10. Polyester Resin Operations; AQMD Rule 1162; South Coast Air Quality Management District: Diamond Bar, CA, amended May 13, 1994. 
Public reporting burden for this collection of information is estimated to average 1 hour per response, induding the time for reviewing instructions, searching existing data sources, gathering and maintaining the data needed, and completing and reviewing the collection information. Send comments regarding this burden estimate or any other aspect of this collection of information, including suggestions for reducing the burden, to Department of Defense, Washington Headquarters Services, Directorate for Information Operations and Reports (0704-0188), 1215 Jefferson Davis Highway, Suite 1204, Arlington, VA 22202-4302. Respondents should be aware that nolwithstanding any other provision of law, no person shall be subject to any penalty for falling to comply with a collection of information if it does not display a currently valid OMB control number.

PLEASE DO NOT RETURN YOUR FORM TO TIE ABOVE ADDRESS.

\section{\begin{tabular}{l|l} 
1. REPORT DATE (DD-MM-YYYY) & 2. REPORT TYPE \\
\hline
\end{tabular} \\ April 2003 \\ Final}

4. TITLE AND SUBTITLE

Cost Comparisons of Oven and Electron-Beam Processing Using Activity-Based

Modeling
3. DATES COVERED (From - To)

March 2001 - December 2002

5a. CONTRACT NUMBER

5b. GRANT NUMBER

5c. PROGRAM ELEMENT NUMEER

5d. PROJECT NUMBER

622618.H80

5E. TASK NUMBER

5f. WORK UNIT NUMBER

8. PERFORMING ORGANIZATION

REPORT NUMBER

ARL-TR-2961

10. SPONSOR/MONITOR'S ACRONYM(S)

11. SPONSORMONITOR'S REPORT NUMBER(S)

Arlington, VA 22203

\section{DISTRIBUTIONAVAILABILITY STATEMENT}

Approved for public release; distribution is unlimited.

\section{SUPPLEMENTARY NOTES}

\section{ABSTRACT}

A limiting feature of electron beam (EB) processing for traditional composite applications is the high cost of processing equipment compared to an oven for elevated cure processing. A model system was developed in SIMPROCESS to compare the net manufacturing costs associated with fabrication of flat-panel glass composite plates using vacuum assisted resin transfer molding in combination with thermal oven curing or EB curing to process composite thermosets. SIMPROCESS integrates process mapping, hierarchical event-driven simulation, and activity-based costing into a single tool and allows accurate computation of industrial costs to be determined under various imposed constraints and economic conditions. In the model evaluation, a determination is made that demonstrates the impact of resin cost on total manufacturing costs for the various components and demonstrates how various scenarios from ownership to toll processing can be implemented by a manufacturer to keep total processing costs from EB curing relatively competitive with oven curing processes.

\section{SUBJECT TERMS}

electron beam, thermal curing, cost savings analysis, VARTM

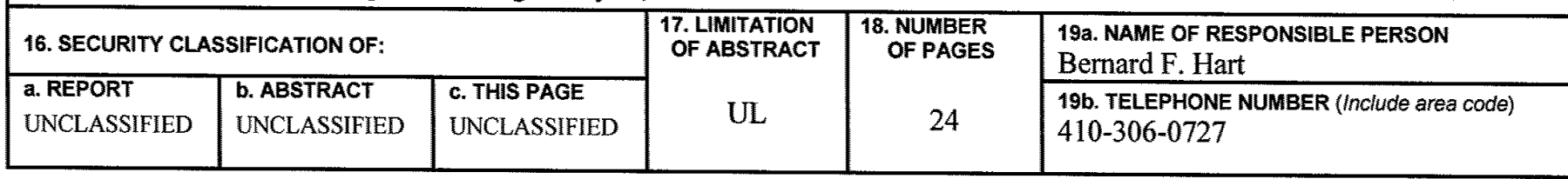


INTENTIONALLY LEFT BLANK. 